\title{
CONHECIMENTO ACERCA DA FAMÍLIA DO PAI ADOLESCENTE OBSERVADO POR MEIO DO GENOGRAMA ${ }^{1}$
}

\author{
Telma Elisa Carraro², Sonia Maria Könzgen Meincke ${ }^{3}$, Neusa Collet ${ }^{4}$, Bárbara Cristina Tavares ${ }^{5}$, Silvana \\ Silveira Kempfer ${ }^{6}$
}

\begin{abstract}
${ }^{1}$ Recorte da pesquisa multicêntrica - Redes sociais de apoio à paternidade na adolescência, coordenado pela Faculdade de Enfermagem da Universidade Federal de Pelotas (UFPel), em parceria com a Universidade Federal da Paraíba (UFPB) e Universidade Federal de Santa Catarina (UFSC), com financiamento do CNPq - processo 551222/ 2007.

${ }^{2}$ Doutora em Enfermagem. Docente do Departamento de Enfermagem e do Programa de Pós-Graduação em Enfermagem (PEN) da UFSC. Santa Catarina, Brasil. E-mail: telmacarraro@ccs.ufsc.br

${ }^{3}$ Doutora em Enfermagem. Docente do Departamento de Enfermagem e do Programa de Pós-Graduação em Enfermagem da UFPel. Rio Grande do Sul, Brasil. meincke@terra.com.br

${ }^{4}$ Doutora em Enfermagem. Docente do Departamento de Enfermagem de Saúde Pública e Psiquiatria e do Programa de PósGraduação em Enfermagem da UFPB. Paraíba, Brasil. neucollet@gmail.com

${ }^{5}$ Enfermeira do Hospital Universitário da UFSC. Santa Catarina, Brasil. barbaratavares22@gmail.com

${ }^{6}$ Doutoranda do PEN/UFSC. Bolsista do CNPq. Santa Catarina, Brasil. silvanakempfer@yahoo.com.br
\end{abstract}

RESUMO: Objetivou-se conhecer, por meio do genograma, os antecedentes familiares descritos pelos pais adolescentes, sujeitos deste estudo. Pesquisa qualitativa, descritiva, exploratória, com técnica de entrevista semiestruturada, momento em que foi construído o genograma, desenvolvida com 41 pais com idade entre 15 e 19 anos, durante dezembro de 2008 a novembro de 2009. Efetuou-se a seleção desses pais a partir de puérperas adolescentes internadas em um hospital universitário de Florianópolis-SC. Os dados foram submetidos à análise de conteúdo. Os resultados ressaltam que a maioria desses jovens pais conhece pouco sobre seus antecedentes familiares, tendo maior conhecimento sobre sua família de primeira geração, desconhecendo a segunda e a terceira, ou pelo menos não mantendo contato com as mesmas. Considera-se primordial o incentivo à família em estar próxima ao pai adolescente ampliando sua condição de cuidado. Estes achados apresentam subsídios para os profissionais de saúde cuidarem e intervirem junto aos pais adolescentes.

DESCRITORES: Paternidade. Gravidez na adolescência. Relações familiares.

\section{KNOWLEDGE ABOUT THE FAMILY OF THE TEENAGE FATHER OBSERVED THROUGH THE GENOGRAM}

\begin{abstract}
The objective was to get to know, through the genogram, the family background described by the teenage parents, subject in this study. The research is qualitative, descriptive, exploratory, with semi-structured interview technique, moment when the genogram was constructed, developed with 41 parents aged between 15 and 19 years old, from December/2008 to November/2009. The selection of the parents was made with postpartum adolescents admitted to a university hospital in Florianópolis-SC. Data were submitted to content analysis. The results show that most of these young parents know little about their family background, having more knowledge about the first generation of their families, unaware about the second and third generations, or at least, not having contact with them. The encouragement of the family is considered essential; they need to be close to the adolescent parent expanding the care condition. These results provide subsidies for the health professionals to take care and intervene together with the adolescent parents. DESCRIPTORS: Paternity. Pregnancy in adolescence. Family relations.
\end{abstract}

\section{CONOCIMIENTO ACERCA DE LA FAMILIA DEL PADRE ADOLESCENTE OBSERVADO POR MEDIO DEL GENOGRAMA}

\begin{abstract}
RESUMEN: El objetivo fue conocer, a través del genograma, los antecedentes familiares descritos por los padres adolescentes, sujetos de este estudio. Investigación cualitativa, descriptiva y exploratoria, con la técnica de entrevista semi-estructurada, el tiempo que se construye el genograma, desarrollado con 41 padres de entre 15 y 19 años, en diciembre de 2008 noviembre de 2009. Hemos hecho la selección de los padres adolescentes después del parto ingresado en un hospital universitario en Florianópolis-SC. Los datos fueron sometidos a análisis de contenido. Los resultados muestran que la mayoría de estos padres jóvenes saben muy poco sobre sus antecedentes familiares, tener un mayor conocimiento sobre la primera generación de su familia, sin darse cuenta de la segunda y la tercera, o al menos no en contacto con ellos. Es considerado primordial el incentivo a la familia estar cerca del padre adolescente en la expansión de su condición de cuidado. Estos resultados proporcionan subsidios para los profesionales de la salud para cuidar y intervenir con los padres y adolescentes.
\end{abstract}

DESCRIPTORES: Paternidad. Embarazo en adolescência. Relaciones familiares. 


\section{INTRODUÇÃO}

O projeto de pesquisa Redes Sociais de Apoio à Paternidade na Adolescência (RAPAD) surge para ampliar os conhecimentos acerca da paternidade na adolescência. Observa-se que existem poucos trabalhos sobre essa temática na enfermagem, sendo evidenciada na escassa produção científica, principalmente ao se avaliar a maternidade, nessa mesma fase. ${ }^{1}$

A adolescência é tratada por muitos como uma fase de rebeldia e desentendimentos. Por esse motivo, o modo de cuidar dos adolescentes que estão vivenciando a paternidade, necessita estar pautado nas relações entre o profissional da saúde e o jovem para que haja acolhimento, vínculo e responsabilização, favorecendo assim a troca de saberes e fazeres entre ambos. ${ }^{2}$

Dessa maneira, estudar a paternidade, em especial, do adolescente, é destacar a dimensão relacional prestada a este, pois serviços de saúde, em geral, direcionam seus trabalhos à mãe adolescente, como por exemplo, o pré-natal. Considerar, portanto, apenas a mãe como merecedora de cuidado e conforto é não compreender que o novo processo de paternar ${ }^{* *}$, aquele cujo pai constitui-se em um membro ativo e participativo na atenção dada ao filho, é mais uma forma de exercício da paternidade. ${ }^{3}$

Contudo, "na abordagem da paternidade na adolescência é imprescindível a visualização do indivíduo integrado ao seu contexto social mais amplo, nas suas relações sociais" ".:44 Assim, inclusive os modos de exercer a paternidade vão sendo alterados nos diferentes momentos históricos.

A partir da década de 1990 houve uma ruptura do modelo hegemônico do exercício da paternidade, aquele modelo tradicional cujo pai era apenas um ator coadjuvante no processo de cuidar dos próprios filhos. ${ }^{5}$ Evidencia-se então o surgimento de um pai que demonstra maior envolvimento e preocupação com a educação e o cuidado dos filhos, deixando de exercer unicamente o papel de pai provedor.

No presente estudo destaca-se o genograma na compreensão do processo da paternidade adolescente, sendo este definido como um retrato gráfico da vida familiar e como um instrumento de avaliação da família. ${ }^{6}$ Por volta da década de 1990, esse instrumento generalizou-se, pois reunia informações sintetizadas dos antecedentes familiares e nível sociocultural. ${ }^{7}$
O genograma é um diagrama que ilustra a composição familiar no decorrer das gerações e das etapas do ciclo de vida familiar, e dos movimentos emocionais a ele associados. ${ }^{8}$ Essa mesma autora revela que as informações reunidas por meio desse desenho da vida familiar podem incluir aspectos genéticos, médicos, sociais, comportamentais e culturais da família, sendo demonstrados os seguintes dados: os nomes e idades de todos os membros da família; datas exatas de nascimentos, casamentos, separações, divórcios, mortes, abortos e outros acontecimentos significativos; indicações datadas das atividades, ocupações, doenças, lugares de residência e mudanças no desenvolvimento vital; e as relações entre os membros da família.

O genograma permite, durante sua construção, a visualização da dinâmica em família e os relacionamentos entre si, em pelo menos três gerações, ${ }^{9}$ remetendo assim para a seguinte questão norteadora do estudo: qual o retrato gráfico da vida sob a percepção de pais adolescentes utilizando o genograma?

Desse modo, a paternidade, nesse período, pode ser estudada e melhor compreendida sob a forma gráfica, viabilizando o objetivo desse estudo, que é conhecer, por meio do genograma, os antecedentes familiares descritos por pais adolescente.

\section{METODOLOGIA}

Trata-se de um estudo qualitativo do tipo exploratório descritivo, no qual participaram 41 pais adolescentes, entre 15 e 19 anos de idade, no período de dezembro de 2008 a novembro de 2009. Efetuou-se a seleção desses pais a partir de puérperas adolescentes internadas em um hospital universitário no município de Florianópolis-SC.

Quanto aos aspectos éticos, obteve-se o consentimento formal das instituições participantes e aprovação pelo Comitê de Ética da Universidade Federal de Pelotas, sob o no. 007/2008. Explicou-se também aos participantes o Termo de Consentimento Livre e Esclarecido que, depois do aceite, era assinado, sendo respeitado o direito de desistência a qualquer momento do estudo, sem prejuízos de ordem alguma. No que tange à preservação da identidade dos pais adolescentes, destaca-se que a mesma foi protegida e o anonimato assegurado. Para tanto, utilizou-se a letra ' $\mathrm{P}$ ' (de Pai), seguida de números ordinais, para a identificação do genograma dos mesmos.

* Paternar, aqui, significa o movimento proativo do pai ao exercer suas funções no exercício da paternidade. 
Exemplo: P. 12. Quanto aos nomes dos familiares e do próprio pai no genograma (Figura 1), os mesmos são fictícios e foram escolhidos pelas pesquisadoras, a fim de preservar o anonimato.
Os familiares do sexo feminino receberam nomes com a letra inicial "M". Já os masculinos, com a letra "A", apenas para melhor visualização e leitura do genograma.

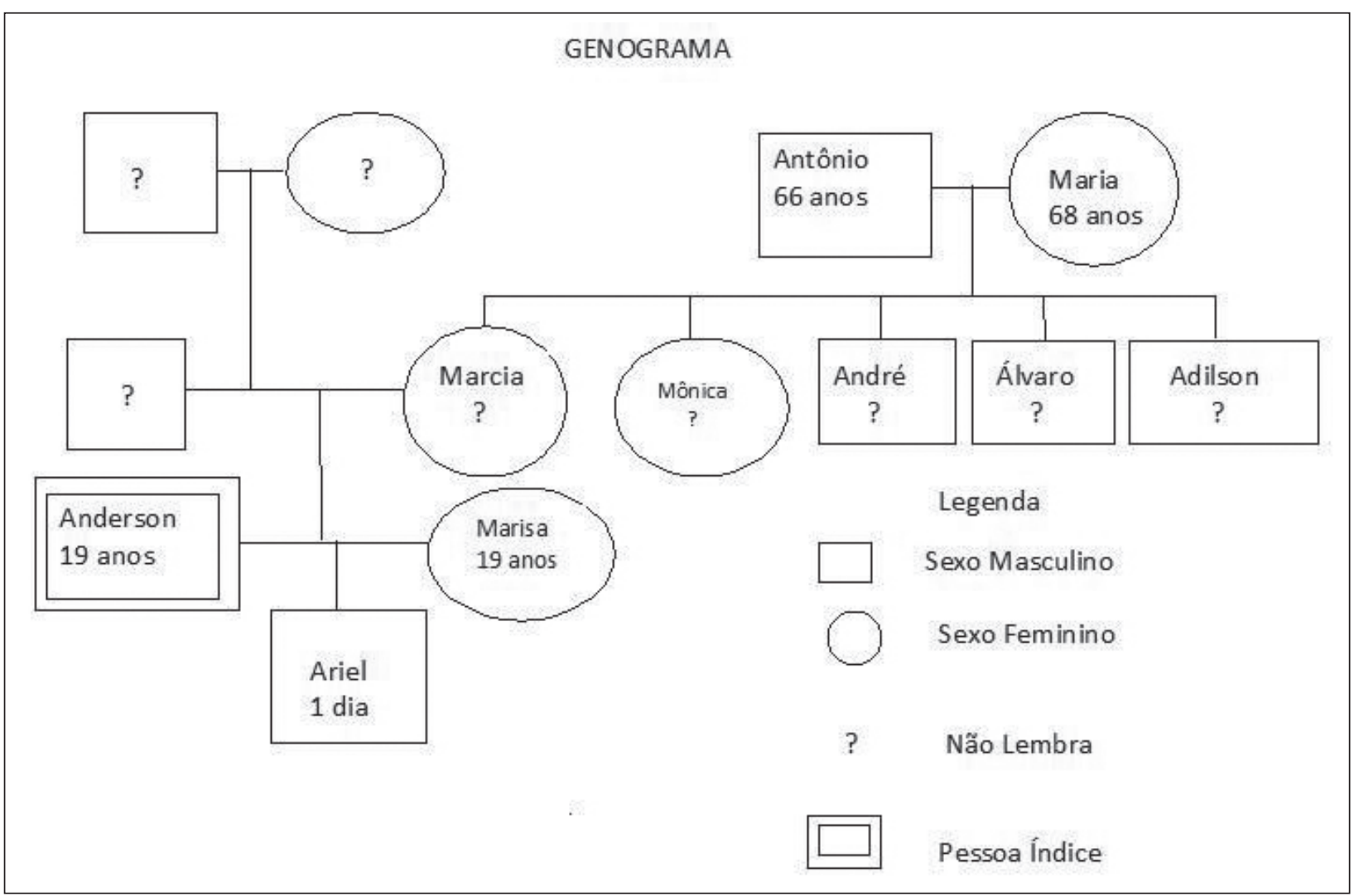

Figura 1 - Genograma elaborado com o pai adolescente P12 durante a entrevista.

Os dados foram coletados por meio de entrevista semiestruturada, realizada no período de até 48 horas após o nascimento do filho, na unidade alojamento conjunto do hospital, momento em que foi elaborado o genograma, em conjunto com o pai adolescente. Nesse processo, ele teve a oportunidade de formar o gráfico de sua vida familiar, relembrando informações como: nome, idade, profissão, data de nascimento ou falecimento, casamento dos familiares. Porém, durante essa construção, o mesmo solicitou, algumas vezes, ajuda da companheira para responder questões referentes aos seus familiares, como: nome, idade, profissão, pois não se lembrava.

As entrevistas foram gravadas e transcritas na forma de texto, sendo os dados tratados conforme a análise de conteúdo. Essa análise aborda técnicas de pesquisa que permitem replicar e validar inferências sobre os dados coletados de uma pesquisa, por meio de procedimentos especializados e científicos. ${ }^{10} \mathrm{~A}$ fase de análise de dados foi operacionalizada, conforme a autora, em três passos: pré-análise, exploração do material, tratamento dos resultados obtidos e interpretação, e descritos pelo uso de frequência relativa, os quais foram organizados conforme apareceram nos genogramas, refletindo a concepção que o pai adolescente tem sobre sua família. A análise dos achados foi conduzida à luz de referenciais teóricos que têm aderência com a temática.

\section{RESULTADOS E DISCUSSÃO}

Foram elaborados 41 genogramas para apresentar as famílias dos pais adolescentes. A família nuclear está representada por pai-mãe-filho. Já a família ampliada ou co-sanguínea está representada por seus pais, avós, tios/as, primos e irmãos.

Os genogramas demonstram dados sobre suas famílias, podendo revelar informações que definem sua história de vida. Porém, neste estudo, os jovens pais lembraram-se de poucos aspectos sobre seus familiares, como se percebe nos dados da terceira geração na qual cerca de $25 \%$ dos entre- 
vistados referiram-se aos seus avós paternos com informações sobre suas vidas, os demais $75 \%$ não sabiam qualquer informação sobre seus avós. Em relação aos avós maternos, relataram mais dados se compararmos com os avós paternos, pois 35,8\% dos pais responderam informações completas destes familiares, o que demonstra que há maior contato do pai adolescente com os avós maternos.

Quando perguntados sobre seus pais, percebeu-se que $35 \%$ dos pais desses jovens eram separados, e que $82,8 \%$ expuseram vários dados referentes à própria mãe. Já em relação aos pais, $63,3 \%$ relataram que sabiam apenas informações como nome, idade, tendo em vista que tem pais separados, ou por não terem conhecido seus pais, ou por que sua mãe possui outro companheiro há muito tempo e o vínculo com o pai biológico é tênue. Por outro lado, quanto aos tios/as paternos e maternos, eles lembraram poucas informações completas, pois desconheciam dados sobre a maioria desses parentes.

Os genogramas elaborados com os pais que participaram deste estudo seguem o formato do apresentado na figura 1. Este se configura como genograma representativo dos demais e ilustra o modo como todos foram construídos neste estudo.

O genograma representativo descreve uma das famílias do estudo, no qual pode-se observar que o pai adolescente conhece pouco sobre seus familiares e mencionou parcas informações sobre a família materna. Quanto à família paterna, não referiu vínculo com o pai, nem com os demais componentes familiares. Estas informações, a partir da legenda, estão representadas pelo ponto de interrogação (?).

Após análise de todos os genogramas, percebeu-se que os pais adolescentes citam com maior ênfase a mãe, o pai, os irmãos e a própria companheira, lembrando de suas idades e detalhes de suas vidas; já os demais familiares, praticamente não tinham informações completas. Esse fato mostra a importância de analisar os aspectos históricos da família ao longo do tempo e entender o distanciamento entre as gerações para compreender o que o pai adolescente sabe a respeito de seus antecedentes familiares.

A visão tradicional de família é organizada por um grupo de pais e filhos, e num sentido mais abrangente, incluem-se antecedentes familiares, como tios, primos, avós, sendo esse um conceito de família nuclear ou extensiva, lembrando que a compreensão da família altera-se principalmente na década de 1990 ? $^{7}$
A família, ao longo da história, vem sofrendo inúmeras mudanças, porém, no presente estudo o pai adolescente considera que sua "nova família" ainda está pautada nos valores da família tradicional, aquela cujo casamento ou união estável é relevante após o acometimento da gravidez. ${ }^{11} \mathrm{Tal}$ situação reforça a égide preventiva ou punitiva, ou seja, o jovem deve reconstruir sua vida por meio de uma união estável ou casamento. ${ }^{3}$

Dessa forma, percebe-se que o modelo tradicional ainda está presente na constituição das famílias, porém os laços familiares encontram-se cada vez mais distantes, em especial na segunda e terceira gerações, uma vez que esse jovem pai pouco ou nada sabia a respeito desses parentes. Em contrapartida, estudos referem que na atualidade ocorre a intensificação no convívio entre avós e netos e, muitas vezes, esse vínculo é mais forte do que entre pais e filhos. ${ }^{7}$ Quando nos reportamos ao genograma representativo podemos observar que o pai adolescente menciona os avós maternos, inclusive registra nomes e idades, fato que demonstra proximidade se comparado aos avós paternos, dos quais não refere nome nem idade.

A paternidade na adolescência é experienciada diante da cultura e valores das famílias, os quais foram construídos com o passar das gerações, ou seja, o que os pais transmitem sobre a história de sua própria família. ${ }^{1}$ Esta transmissão decorre das relações familiares pautadas na intimidade e comunicação. ${ }^{12}$ Porém, em nosso estudo, notou-se que essas relações tradicionalmente encontradas na família sofreram modificações ao longo das gerações, uma vez que os pais adolescentes pouco ou nada sabiam a respeito de seus familiares, como podemos observar no genograma representativo.

Considera-se neste estudo a estrutura familiar como externa e interna. A interna é aquela composta por sua mãe, pai e irmãos, e a externa, pelos demais familiares de segunda e terceira gerações. Nesse modelo é importante, ao estudar a família, verificar se há comunicação entre seus membros e interação entre eles, mesmo que distantes geograficamente. ${ }^{13}$ Nesta pesquisa os dados apontam que a família externa pouco é referida pelo jovem pai, quando questionado sobre sua parentela. Este fato, por um lado, pode denotar a pouca comunicação e interação entre os membros da família, por outro pode-se deduzir que o adolescente não se preocupa em manter estes laços parentais. Na maioria dos genogramas analisados o individualismo nas relações pessoais ou familiares intensifica o distanciamento entre 
o pai adolescente e seus familiares. A identidade dos familiares é expressa pelos jovens, de forma sucinta e, muitas vezes, sendo necessário o auxílio da companheira para responder.

A partir destas colocações, vale salientar que embora o modelo nuclear de família seja atualmente questionado ${ }^{12}$, a família desse jovem não é suprida por nenhum outro grupo social de apoio. Segundo os mesmos autores, concomitantemente a isso, surge o individualismo, o qual leva a flutuação das identidades individuais e das relações familiares. Neste estudo surgem, também, pais que demonstram o conhecimento, a interação e a comunicação com a família, pois elaboraram o genograma com dados de três gerações. Pode-se observar, no genograma representativo apresentado, a existência de maior vínculo do adolescente com a família materna do que com a paterna, fato que também surgiu com outros pais do estudo, e podemos depreender daí que esta ligação pode acontecer com um dos ramos da árvore genealógica.

A família compõe-se por seres humanos, ligados por laços consanguíneos, de adoção, interesse ou afetividade, no transcorrer de seu desenvolvimento, e traz junto a ela valores e sentimentos aprendidos e que fazem parte de sua história cultural. ${ }^{14}$ Os dados deste estudo apontam que ao não se recordar da história de sua família, a maioria dos pais adolescentes revelou que os laços familiares sofrem modificações no decorrer dos tempos, haja vista a família apresentada no genograma representativo aqui registrado.

Nesse processo, histórias vão sendo perdidas, vínculos tornam-se fragilizados ou inexistentes, contatos entre os membros da família extensa ficam cada vez mais distantes e vulneráveis, implicando em profundas mudanças nas relações familiares.

\section{CONSIDERAÇÕES FINAIS}

A utilização do genograma proporcionou o entendimento do retrato familiar dos pais adolescentes participantes do estudo, uma vez que esse instrumento deixa mais evidente a formação da família e o conhecimento acerca de seus antecedentes familiares.

Os dados do estudo demonstraram que os pais adolescentes têm maior conhecimento das informações sobre sua família de primeira geração, desconhecendo a segunda e a terceira, ou pelo menos não mantendo contato com as mesmas.
Vivenciar a paternidade na adolescência implica em mudanças significativas na vida do jovem. Para tanto, o apoio e a proximidade da família são fatores importantes a serem destacados, pois ao aproximar gerações poder-se-á mobilizar esforços para as modificações de papéis, minimizando riscos sociais decorrentes das mudanças impostas pela nova vida.

Enfatiza-se a importância de apoiar os homens nessa fase para que possam experimentar a paternidade responsável com todas as alterações que a mesma desencadeia. $\mathrm{O}$ genograma constituiu-se em instrumento que viabilizou conhecer o que os pais adolescentes sabiam sobre seu contexto familiar e isso contribui para que os profissionais de saúde busquem a compreensão do modo como cada jovem pai vivencia essa experiência.

Portanto, este estudo oferece aos profissionais de saúde, principalmente àqueles que trabalham com pré-natal, subsídios para ampliar seu olhar e seu fazer, para que possam incluir em suas agendas além dos cuidados com a mãe, também com o pai adolescente.

\section{REFERÊNCIAS}

1. Meincke SMK, Carraro TE. Vivência da paternidade na adolescência: sentimentos expressos pela família do pai adolescente. Texto Contexto Enferm. 2009 Jan-Mar; 18(1):83-91.

2. Maturana HCA, Progianti, JM. A ordem social inscrita nos corpos: gravidez na adolescência na ótica do cuidar em enfermagem. Rev Enferm UERJ. 2007 Abr-Jun; 15(2):205-9.

3. Correa ACP, Ferriani MGC. Paternidade na adolescência: um silêncio social e um vazio científico. Rev Gaúcha Enferm. 2006 Dez; 27(4):499-505.

4. Luz AMH, Berni NIO. Processo da paternidade na adolescência. Rev Bras Enferm. 2010 Jan-Fev; 63(1):43-50.

5. Orlandi R, Toneli MJF. Sobre o processo de constituição do sujeito face à paternidade na adolescência. Psicol Rev. 2005 Dez; 11(18):257-67.

6. Pereira APS, Teixeira GM, Bressan CAB, Martini JG. O genograma e o ecomapa no cuidado de enfermagem em saúde da família. Rev Bras Enferm. 2009 May-Jun; 62(3):407-16.

7. Machado HB, Soprano ATB, Machado C, Lustosa ACP, Lima MH, Mota ACG. Identificação de riscos na família a partir do genograma. Fam Saúde Desenv. 2005 Mai-Ago; 7(2):149-57.

8. Wendt NC, Crepaldi MA. A utilização do genograma como instrumento de coleta de dados na pesquisa qualitativa. Psicol Reflex Crit [online]. 2008 [acesso 2010 Set 20]; 21(2):302-10. Disponível em http:/ / 
www.scielo.br/scielo.php?script=sci_arttext\&pid $=$ S01027972200800020001\&lng $=$ en\&nrm $=$ iso

9. Nascimento LC, Rocha SMM, Hayes VE. Contribuições do genograma e do ecomapa para o estudo de famílias em enfermagem pediátrica. Texto Contexto Enferm. 2005 Abr-Jun; 14(2):280-6.

10. Minayo MCS. O desafio do conhecimento: pesquisa qualitativa em saúde. $11^{a}$ ed. São Paulo (SP): Hucitec; 2008.

11. Rios MG, Gomes IC. Casamento contemporâneo: revisão de literatura acerca da opção por não ter filhos. Estud. Psicol. 2009 Abr-Jun; 26(2):215-25.
12. Ponciano ELT, Feres-Carneiro T. Modelos de família e intervenção terapêutica. Interações. 2003 Dez; 8(16):57-80.

13. Schwartz E, Lange C, Meincke SMK, Heck RM, Kantorski LM, Gallo CC. Avaliação de famílias: ferramenta de cuidado em enfermagem. Cienc Cuid Saude. 2009; 8(Supl):117-24.

14. Meincke SMK. A construção da paternidade na família do pai adolescente: contribuição para o cuidado de enfermagem [tese]. Florianópolis (SC): Universidade Federal de Santa Catarina, Programa de Pós-Graduação em Enfermagem; 2007. 